\title{
Detección proviral de HTLV-1 mediante reacción en cadena de la polimerasa (PCR)
}

Carlos Sevilla, Jorge Alarcón, Alina Huiza, César Gutiérrez, Marcos Ñavincopa, William Cornejo, Abraham Cáceres, Abelardo Tejada, Franco Romaní, Nicanor Mori, Paolo Wong, Víctor Huamán, Rubén Vásquez, Romina Tejada, Alitza Flores, Milena Alfaro, Esther Valencia, José Gonzales

D.A. Microbiologia Médica, Facultad de Medicina, UNMSM

Objetivos: Detectar el genoma proviral de HTLV-1 mediante el desarrollo de reacción en cadena de la polimerasa (PCR).

Diseño: Descriptivo.

Institución: D.A. Microbiología Médica, Facultad de Medicina, UNMSM.

Participantes: Personas con y sin sospecha de HTLV-I.

Principales medidas de resultados: detección de HTLV-1 mediante PCR.

Resultados: El $71,4 \%$ de los pacientes con sospecha clínica de HTLV-I fue reactivo por métodos inmunológico. Elisa HTLV I-II Biokit detectó 5 casos reactivos ( $X=2,359 \pm$ DE: 0,7309); los dos casos con sospecha clínica de HTLV- I fueron no reactivos (DO: 0,007 y 0,04); los tres casos con antecedente clínico de estrongiloidiosis fueron no reactivos al Elisa (DO: $0,029,0,001$ y 0,00). El promedio de los sueros no reactivos con antecedente clínico de HTLV-1 y estrongiloidiosis fue $0,0154 \pm 0,018$. En el grupo de voluntarios sanos, el promedio de las DO fue $0,0085 \pm 0,0068$. Al comparar los grupos, se observó que hubo diferencias significativas entre el grupo HTLV-1 y los grupos estrongiloidiosis y controles sanos $(p<0,05)$. La amplificación del ADN gonómico (proviral) de muestras sanguíneas utilizó primers de la región Pol I.

Conclusiones: El método inmunológico permitió diferenciar los grupos de estudio. El producto de amplificación de los pacientes con HTLV-I fue de $117 \mathrm{pb}$.

Palabras clave: HTLV-1, Elisa HTLV-I/II, PCR.

\section{Optimización de técnicas para aislamiento y ruptura de quistes de Giardia spp}

Ana Huamán, Hilda Solís, Luis Marocho, José Guevara, Gloria Sáez, Esther Valencia, Mario Tapia, Sofía Espinoza, Susana Padilla

Instituto de Medicina Tropical Daniel A. Carrión, Facultad de Medicina, UNMSM

Objetivos: Optimizar y evaluar técnicas de ruptura de quistes de Giardia spp para obtener ADN, paso previo a pruebas moleculares.

Diseño: Experimental.

Institución: Instituto de Medicina Tropical Daniel A. Carrión, Facultad de Medicina, UNMSM.

Material biológico: Muestras de heces con quistes de Giardia.

Intervenciones: Las muestras de heces con abundantes quistes de Giardia fueron evaluadas con una técnica de obtención de quistes y tres de desenquistamiento. Técnica 1: sedimentación rápida; el sedimento fue lavado varias veces con agua destilada y centrifugado. Para el desenquistamiento, los quistes fueron incubados a: Técnica A: $37^{\circ} \mathrm{C}$ con bilis de cerdo. Técnica B: con $\mathrm{HCl} 0,1 \mathrm{~N}$ y luego hipoclorito de sodio al $20 \%$ a $37^{\circ} \mathrm{C}$. Técnica C: Por duplicado, cinco ciclos de congelamiento $\left(-20^{\circ} \mathrm{C}\right)$, calentamiento $\left(80^{\circ} \mathrm{C}\right)$ y luego papaína a $60^{\circ} \mathrm{C}$. Se contó en cámara Newbauer el número de quistes antes y después de cada prueba.

Principales medidas de resultados: Mayor número de trofozoítos.

Resultados: La técnica B rindió mayor número de trofozoítos que la $\mathrm{A}$. La $\mathrm{C}$ no tuvo éxito.

Conclusiones: Desenquistar con $\mathrm{HCl} 1 \mathrm{~N}$ e hipoclorito de sodio al $20 \%$ a $37^{\circ} \mathrm{C}$ fue buen método para obtener trofozoítos de Giardia.

Palabras clave: Desenquistamiento, quistes de Giardia spp. 